\title{
IMPOSSIBLE EMOTIONS: THE ETHICS OF MOURNING AND MELANCHOLIA
}

\section{Tirna Chatterjee*}

\begin{abstract}
This paper looks at mourning and melancholia, and their ethical implications through the work of Sigmund Freud and mostly Jacques Derrida. The attempt here is to read through Derrida's auto thanatological oeuvre through questions of fidelity, interminability, impossibility and ethics. In our perpetual struggle as scholars dealing with questions of meaning, existence, loss, life and death this paper tries to navigate the discursive traditions of looking at mourning and melancholia and what their radical potential is or can be where the mourning; melancholic; haunted; living subjects bear an impossible task unto the dead.
\end{abstract}

Keywords: mourning, melancholia, death, loss, ethic

*Tirna Chatterjee, PhD Scholar, School of Arts and Aesthetics, Jawaharlal Nehru University, New Delhi, India e-mail: chatterjeetirna@gmail.com | ORCID: https://orcid.org/0000-0002-0285-0100 
Jacques Derrida (2005) wrote in Rams: Uninterrupted Dialogue Between Two Infinities, the Poem:

"For each time, and each time singularly, each time irreplaceably, each time infinitely, death is nothing less than an end of the world. Not only one end among others, the end of someone or of something in the world, the end of a life or of a living being. Death puts an end neither to someone in the world nor to one world among others. Death marks each time, each time in defiance of arithmetic, the absolute end of the one and only world, of that which each opens as a one and only world, the end of the unique world, the end of the totality of what is or can be presented as the origin of the world for any unique living being, be it human or not." (p. 140)

We, as thinking, feeling human beings, constantly struggle with the question of mortality, our own and of those around us. We take clinical, thought-out, rational decisions like wearing helmets, taking vitamins, or getting medical care to delay death. But death is the palpable design of life, it's the pivot around which everything is built, nothing - not a single living organism - is exempt from death, the circle of life is only a circle because of death and its inevitability. And mourning is that unique, personal thing which has been the concern of thinkers, philosophers, artists, communities, religions and everyday people.

Death, in the simplest terms, is the loss of the other - a person; an idea; a relationship and mourning is presumably that which comes after - a response to loss. The dead are gone, but weare left to rearrange their remnants and reminders within us. Recognising what is evidentially gone is only a miniscule part of the whole complex of mourning and the other part is the enduring connection with loss. Many have agreed that there is "nothing more human than mourning" (Krell 2000: 2) and the ability and faculty for mourning, if ignored, would mean to not notice what philosophers and thinkers have called the essence of human being. Mourning is a complicated operation which combats and trammels the possibility of any 'ultimate' meaning. It is pertinent to wonder whether it is a process or an act; a feeling or an emotion; an affect or an event. 
The experience of loss of someone in its absoluteness i.e in death, provokes the labours of mourning wherein one of its purpose, if one could crudely call it that, is a shielding from the dead rendering it to be retroactively a question about the place in the world that is still held by the other (Spargo 2004: 6).

This paper is an attempt to talk about death, mourning, melancholia and the meaning of life (and death) through mostly J acques Derrida's extensive body of work, especially on death and mourning and the critical work done on his oeuvre by Bennington (2010), Davis (2007), Gaston (2006), and Royle (2009).

The contention of this paper is similar, mourning is an acutely ethical question as it is necessarily a question about the complex relationship between the other and the self and the otherness within the self. Studying mourning prompts many questions such as how does one mourn? What does it mean to mourn? When or how does mourning begin? Or end? Who mourns? How does the mourner recover? Do they ever recover? Therefore, mourning here is looked at as an ethical negotiation which addresses the other and the self.

\section{Mourning and Melancholia: The Impossible Processes}

For this paper, it is important to differentiate between these two responses to loss: mourning and melancholia, which are integrally rooted in one another (Davis 2007: 131). Both deal with grief experienced by us when we are faced with the loss of a significant person, a thing, or an ideal. Melancholia has been described as a distinct disease with specific mental and physical symptoms since way back in the 5 th and 4 th centuries BC.

Much of the contemporary discourse on melancholia is largely rooted in propositions put forth by Sigmund Freud in his 1917 essay, Mourning and Melancholia where he deemed the two concepts to be separate as well as independent. Mourning, Freud noted, is the absolute 
severance from 'normal' behavior (positing that there is a normal behaviour, i.e. a state of non-mourning), coupled with the exhibition of losing interest with and in the outside world. In more intense cases, mourning means the out-and-out denial of any new object or a complete refusal to take part in any action that is not in regards to the lost object.

In the realm of this understanding, mourning is deemed as a normal if not natural reaction to loss where the mourners are not just allowed to recuse themselves from what is the everyday behaviour of normal, but they are encouraged to display their grief in and through mourning by participating in rituals or in expressing non-normative (or loss appropriate) behaviour. The "work" of mourning or the goal that mourning sets to acquire is to bring the mourner back to the erstwhile normal. Through what Freud (1917) refers to as "reality-testing" the subject will be able to understand that the love object is now dead and the libidinal attachment therefore would be concluded completely only to be focused on a new object (pp. 204-205). One can say that to Freud, mourning "is not simply an emotion... but the performance of a work that... is a psychically transformative activity" (Ricciardi 2003: 21).

This process is presumed to be prolonged, difficult, and arduous but in the Freudian framework it is not interminable; rather it can be concluded when libidinal attachment is focused on to a new object of love. Ricciardi (2003) suggests that Freudian psychoanalysis is essentially a modernist discipline, for not only does it historically coincide with the emergence of high modernism, but also because the workings of psychoanalysis is contingent on the "hermeneutics of fragmentation and the interiority... of the psyche" (p. 17).

To Freud (1917), the major ways in which melancholia and mourning vary from one another is that the melancholic is underlined by rebuking if not blaming the self and expecting punishment for it (p. 204). Pertaining to the question of duration, mourning and melancholia, according to Freud, are different because mourning regardless of how tenuous a process can be concluded at some point but melancholia is 
indefinite, even unending, and can only end with the death of the melancholic subject.

Freud was aware of the need for his framework for mourning and melancholia to be further conceptually developed because, to him, mourning is the natural response to loss, and therefore essentially not pathological and the behaviours which ensue in the state of mourning are that which can be accounted for. But melancholia has been historically pathologized for it has remained incomprehensible, unfathomable, ambiguous, denying any possibility or sense of realization or resolution. Melancholia is always in progress with no promise of conclusion.

Therefore, to reiterate the Freudian logic, melancholia would be an ongoing, halted process where the melancholic subject is consumed by the past, ceaseless repetition linked to the lost object of love in a selfabsorbed manner; whereas mourning is a process with the promise of an end and the resumption of something else. And mourning, according to Freud, can occur pertaining to an array of plausible abstractions which can go beyond the self (identity).

This is a recognition of the radical ethical and political potential of mourning which also necessitates us to ask the question- why is mourning (so often) unsuccessful? And Freud was never short of answers. Melancholia (as unsuccessful mourning) could be in reaction to an ideal of loss and not the reality of the loss, where mourning might not have concluded because the object of love may still be alive but the ideal, the object represented, may have been lost.

But melancholia renders the subject unable to put the process of mourning to rest, for it could exist outside of the subject's capabilities to recover the lost object and/ or transfer the attachment to a new love object or to sense an ambivalence towards it. And the melancholic may find it impossible to comprehend what exactly has been lost or even what that loss implies. So, if the lost object is obscured then any 
plausible conclusion to mourning is lapsed rendering it unsuccessful and incomplete.

The denial of mourning is what separates melancholia from mourning as J udith Butler (1990) notes that, "the melancholic refuses the loss of the object... because the ambivalence felt toward the object requires that the object be retained until the differences are settled" (p. 61).

Freud opined that mourning loses the traumatic vitality where the mourner disinvests from the dead person(s) or lost ideal(s) by allowing ourselves to be engaged with new objects; distracted by other things; the trials and tribulations of everyday life; by not being dead/absent themselves. Whereas melancholia is that lingering sadness where the affect remains with the lost object as we, the alive subject, are unable to consciously understand what is it that we have lost. The melancholic subject can still be or become aware of the 'who' they have lost but not the 'what' of the other they have lost.

The melancholic subject tries to forestall complete and abject loss by keeping and integrating the lost object in/into themselves. It is this process and act of internalization which becomes part of the procedure through which the melancholic subject refuses to let go of that which/who is lost, abjuring and/or delaying the identification of tolerating loss. It could seem that the predicament involves living in the past as opposed to the present.

But it is not simply a matter of experiencing the past as if it were the present; it's a shift in the form of temporal experience. Any act or attempt at preservation of the practically designed world relies on a lack of acceptance of future possibilities, which therefore can make us ponder over loss. One's sense of the immediate and the future is altered; that excludes any anticipation for or realization of events that bear the ability to restructure our lives.

To Merleau-Ponty (2012), this is not a concern of tedious connections or of intent or even of desires, which are limited by the realm of our consciousness, but singular and phenomenologically 
fundamental (and indeed fundamentally phenomenological) to "being in and toward the world" (p. 80).

Derrida, on the other hand, sees the act of reckoning with death and the dead as a self-reflection which is supposed to be taxing and allconsuming, for it is a continued labour of internalisation of the other unto and within the self. This bears the potential to absolutely engulf the other in their death, vis a vis in their absence. Pertinently, the contact of the mourning subject with the dead/ other becomes about experiences which are not essentially there to be accessed on command for the conscious mind, but it is there. Freud sees the melancholic in their resistance to mourning while remitting them to a state which precedes the loss, the alleged state of the non-mourning 'normal'. The melancholy subject is then to be held accountable for bearing the other through keeping alive that which is within the self by thinking about the questions and dilemmas of living / life, dying / death and existing / existence.

Freud's (1917) framework can be seen, at least to a certain degree, as the unacknowledged, yet an adeptly apparent, background for and implicit references to Derrida's understanding of mourning (Davis 2007; Miller 2009). It'd be a disservice to impose that unto the Derridean conceptualization (Davis 2007: 132) but it is of utmost importance to understand and account for the fact that there are apparently vague and plausibly reductive threads that can be traced linking the melancholic subject(s) in both Derrida and Freud. It is therefore vital to read Derrida's idea of interminability as free of Freud's assertions so as to not pathologize Derrida's understanding and also to not fall into the trope of appropriating Derrida's contentions onto that of Freud's.

Following Derrida, the process of mourning is not determined by time; it's rather non-stop, ceaseless, and 'interminable'. There is no offer of resolution for mourning in Derrida's account, for it cannot be reduced to being prompted by the death of the (significant) other but as 
initiated by the knowledge of the very process of dying which is continuous, definite and finite i.e. in death; complete absence; abject loss. Mourning then both precedes death and also comes after it. The question of one's mortality is presaged by the many continued losses of others even when thought and knowledge are temporarily suspended (Davis 2007: 129).

Indeed, the death of the other can render thought to stop or words to not form, but one is compelled to think about it and resist the will to remain silent and maybe even unwittingly participate in the acts of mourning- through rites, rituals, designs, and structures. But Derrida warns us of the 'narcissistic potential' in the living to appropriate the other completely in the process of mourning for the responder is now gone, no longer qualified to respond or to be responsive. In the act of mourning, one is presented by a "paralysing double-bind" where it is both impossible to speak about it and impossible not to (Royle 2009: 70). The absolute other, who in death is reduced to images or statistics for us, is resistant to "the closure of our interiorizing memory" (Derrida 2001: 34). So, we as the mourning subjects have to look 'in' us.

The process and logic of interiorization can't assign limitations reductively between that which is on the outside and that which is on the inside, which translates to mean the self and the other; the "other dead in us" as still other (Derrida 2001: 52). The assertion is that the otherness of the other is to be maintained while being internalized. That which is left behind for the mourning subject is what Derrida (2001) deems 'memories and monuments' which can translate to mean that which is "no longer anything but images" (p. 159), images which are doomed and deemed to be interiorized because the dead 'other' can not but be "in" the mourning subject. For the dead other, the mourning subjects are left with the only remnants i.e. images which imply that the dead are recollected and represented through language, thoughts, and images. But also, the dead cannot be represented justly in images for it 
resists any medium that tries to recollect or remember them completely.

Derrida (1989) writes that whenever we register, acknowledge or respond to the significant other as "gone forever" it's "unfaithful to delude oneself into believing that the other living in us is living in himself" (p. 21). So even as the dead significant other can remain within the mourning subject (us) they do not belong to us, they are not available to us, and they are not accessible to us. Therefore, for there to be a reckoning with the dead, it is strictly and solely contingent on the ones still left alive (Brault \&Naas 2001).

This untethered and uncontrollable reality of death and the dead remaining with/in the mourning subject (as images) does not and can not presume that the living can command or posit ownership of the images (as and of the dead) and memories in the process of interiorization, a process that can never be conclusive and complete and is therefore doomed to be and inevitably remains, impossible. Derrida (2004) says: Mourning must be impossible. Successful mourning is failed mourning... (it) enjoins me not to succeed in the work of mourning: the other must remain the other... if I take into me as part of me... and if... I "narcissise" this death of the other by a successful work of mourning, I annihilate the other. (Translated by Royle 2009: 135) ${ }^{1}$

Derrida's understanding of death can largely be an inquest into the interiorization of that which can not be interiorized (Brault \& Naas 2001: 11). It is resistant to any form of appropriation; that which is transcending and negotiating mournful memory as it also concurrently and contradictorily inaugurates it (Derrida 1989: 38). This impossible process and act is complicated by that which is absorbed by the mourning subject post the death of the significant other without gauging the implications of it because it is impossible to name, express, access or understand. The aporia of taking in that which can not be

${ }^{1}$ See further Derrida in Conversation with Elizabeth Roudinesco (2004) translated by (Royle 2009). 
taken in, at least not necessarily realized by the conscious mind, figures as the pivotal source of the mourning subject's ethical question, duty and "the unbearable paradox of fidelity" (Derrida 2001: 159).

The "unbearable paradox of fidelity" is (doomed to be) incomplete because it can't have a fixed meaning. There's no way to reduce the loss with death being the only conclusion because while the mourning subject is alive they are living with the forever incomplete interiorized death of the other in them. There's therefore no way to be 'done' mourning and that which is in the mourning subject (us) doesn't belong to us (as mourning subjects) because the images (as all that is left of the dead other) may remain with us but that which precedes and succeeds us, is precisely where our ethical responsibility originates (Brault \& Naas 2001: 11).

The absolute otherness of the other is infinitely, consistently and perpeually beyond the mourning us, so that though certain (images, memories, feelings, qualities) relationships of significance can be forged with the dead other, i.e., a degree of interiorization, an actual implication of it remains impossible for the conscious mind to grasp. Therefore, impossibility is the process. Derrida (1989) writes that "death constitutes and makes manifest the limits of a me... who are obliged to harbour something that is greater and other than them; something outside of them within them" (p. 34). This implies that even the impossible is possible, which dictates that the "rhetoric of mourning" has to fail so as to succeed (Derrida 2001: 144).

If interiorizing the other with absolute fidelity were a plausible proposition, then the other would cease to be the other and become abjectly colonised, completely annihilated and therefore mourning would have failed. And an "aborted interiorization is... a respect for the other as other" (Derrida 1989: 35).

Herein, that failure succeeds, that is, the ceaseless, unending, interminable interiorization is always unaccomplished and forever unaccomplishable. Mourning is imperative, but it fails to happen, it fails 
in happening, it never completely finally happens, except in failing, therefore, it is always incomplete. And this we have to carry in us through endless mourning and melancholia as the "world after the end of the world" (Derrida 2005: 140).

This "terrible logic of mourning" is underlined in Derrida (1995) when he writes that: "I cannot complete my mourning for everything I lose, because I want to keep it, and at the same time, what I do best is to mourn, is to lose it, because by mourning, I keep it inside of me" ( $p$. 152). This schema of mourning is the difficult prerequisite which furnishes the plausibility of "true mourning (as) impossible" (Derrida 1989: 35), so that anyone who attempts the work of mourning has to learn the impossible, i.e., "mourning is interminable." (Derrida 2001: 143).

This 'work of mourning' (Freud 1917; Derrida 2001) demands constant and rigorous labour to endure the aporia. It is a question of our responsibility to the dead significant other and how and to what degree are we able to relate with the other without taking away that which is unique and or incomparable rendering it generalized. We, the mourning subjects, in the midst of death everyday, in terms of dead ideals and dead close ones, have to take the dead unto ourselves so as to be able to locate the other and relate to the other to allow internal conversations to take place with them so that we can with respect and fidelity carry them on.

Considering the uncompromising and ceaseless nature of mourning, the will is vital, to take the other in us for it does not come without the risk of colonizing the unique other unto ourselves and losing the other to us. The mourning subject is therefore bestowed with the remarkable and impossible duty to allow the other to speak. We, the mourning subjects, have to constantly negotiate our ethical disposition to the dead/ other, we have to respect the otherness and the singularity of the other as we have to reconcile and moderate our desire to speak with the dead. 
This double bind of desire is not only an impossible desire but also a desire for the impossible for when we have lost a friend or loved one to death, we can no longer lose them and they are within us so they are also at their most proximate to us. They belong within us as more than a part of us but a part of history which means they are no longer that unique, singular other which initially made us responsible for them (Brault \& Naas 2001: 27)

That is precisely what we are also set out to lose, the singularity, which keeps gnawing at the memory which is contingent on the "essence" or the ephemeral, presumed moments of absolute events and encounters of which repositories are now remiss of any archive or words. It is about those bursts of laughter minus the joke or the snippet of a conversation or the curve of the lips and glimpse of a chipped front tooth, a postcard sent from a faraway city or the distinct dots on i's and j's or the last, chance meeting at a now gone flower shop, all bear the mark of "secret"2 languages which are intimateand inimitable (Derrida 2001: 38) and not susceptible to confinement, limitation or even a name (Brault \& Naas 2001: 30).

The Unthought Known

The complexity of mourning is acutely about the experience of interiorization of the memories collected by the mourning subject of the now dead other. Mourning, as an emotion and an affect is that which is rooted and realized in memory. But this experience as memories, be it of an emotion, a feeling or an affect or the experience of an event, is not necessarily imagistically representable where one can slip into the 'unthought known' (Bollas 1987). The known is the constantly repeatable, experiential being which is quite simply the experience of our being, and of existential knowledge. These are impossible to think of in any conceptually acknowledgeable logic. This seat of the

${ }^{2}$ See Derrida (2001) for the use of the word secret. 
unthought known is where the unraveling of one's own ease under pretensions, masking as knowledge, slips into a place that is beyond thinking (Ibidem).

This unthought known is beyond representation, it cannot be coded in word, it's beyond the realm of cognition or communication, it's beyond the imagistic and beyond abstraction. It is an existential question, a question of being. These unnameable moments, no matter how real or unreal, are ultimately rendered impervious to becoming a memory. Thus, that which is internalised of the dead significant other in and by us, the mourning subject, is inaccessible and irretrievable and the memory of the other is completely engulfed. The dead other was both an object within one's world and a condition for understanding it where the absolute acknowledgement of loss would imply that that world is rendered forever disturbed (Ratcliffe 2017). Therefore, the death of the significant other brings the alive subject who is the mourning subject to a halt, i.e., a world which was experientially shared, felt, and realised among them is now left solely to the mourning subject but as perpetually interrupted.

Derrida (1989) asserts that there is an omission within the process of interiorization that has very little relation to the determinate and limited scope of memory; it has more to do with the design of the relationship unto the other that renders the lettering of memory as a complete dismantling of interiorizing (p. 56). Somewhere amidst that which is recalled or recollected after the death of the significant other and that which was felt and experienced in the design of our 'unique' lives lived with and amongst the other, there is a rupture where memory can but fail to mean anything in the realm of cognition. And the limitedness of memory is patterned with feelings and experiences of disruptions and dissonance that are witness to the difference between the other and the self. The dead other in its absolute and unique singularity perorates itself unto the self, the mourning subject, us, 
where we fail to adjourn the death of the significant other who is forever elusive and forever in the past (Derrida 2001: 39).

Mourning begins the moment a significant relationship is forged, way before the event of death, therefore interiority is continuous, repeatable, and perpetual (Ibidem: 46). Mourning takes place in advance, implying that the death of the other does not imply that we, the mourning subjects, can be free of the spectres. Rather it is in that very rupture that both mourning and haunting are released (Derrida 2002: 132).

And none of us, the living among the dead, are exempt from that nagging anxiety and anticipation, for the absolute and definite nature of death, that colours any and every relationship. Mourning both succeeds death and is also 'prepared' before it actually happens. Other than abject denial, there really is no relationship minus the knowledge of this finiteness and each and every thing we etch onto the present part of our relations to others is always already bearing the mark of memories of the dead. Indeed, we attempt imaginations which precede the actual event of death, a world where we or the significant other is no longer alive but when this event arrives, which one may have preempted, imagined, even prepared for, the experience is always 'unique' which implies that it is the/an end to the/ a world (Brault \& Naas 2001: 15).

Therefore, in the death of the significant other death comes to us as well, the mourning subjects (Derrida 1989: 28). This prompts contemplation over our own mortality taught to us by death and by the other. Learning to live is learning to die and living beyond the dead or living beyond the death of the other is not to simply remain but bear the ethical plight which necessitates our entangling with the meaning of living along with death. Remarkably it is death that is the very precondition to living and living is only poignant against the consideration of the fact of death as absolute, definitive, finite and limited. 
Living Among Ghosts: The Dead Other and the Haunted Self

Derrida (1994) saw life as "maintain(ing) itself with some ghost" (p. xvii) and the dead other (person or ideal) will forever haunt the mourning subject where the ghost is "the completely other, dead, living in me" (Derrida 2001: 41). The ghost points to the intervention of the other into the self which simply translates to mean that the haunting of the other is in the self (Derrida 2001a: 89). Haunting, suggests the effect of the other on and in the self, that impossible, forever other which can but shouldn't be appropriated unto the self. This haunting is ceaselessly moving with no promise of respite; resolution; reconciliation; or closure, where the act, labour and process of mourning is continuous only in interrupting agency and disrupting control while trying to gauge what is lost when loss is experienced. This is received as an inheritance that is not accumulated or is in unison even with it's self, but from a "secret" of the ghost (Derrida 1994: 16).

This secret is unruly and lopsided, doomed to be forever disproportionate to the absolute knowledge and understanding of death. To Derrida (1994) the ghost is "something that one does not know precisely... if it exists, if it responds to a name and corresponds to an essence." (p. 6). It is unknowable to us not out of ignorance but because the non-object, the 'non-present present' which (can/does) no longer belong to neither a kind of known knowledge nor to what one thinks one knows as knowledge (Derrida 1994).

The ethical responsibility rests here, wherein we have to learn to live in the company of the spectres of those dead, of living with the other, of living while haunted. The surviving, alive, mourning subject is haunted by the acts and enactment of mourning for our losses; in our yearning to deal with the event of the death; and the process of loss (Davis 2007: 129). We, the alive, haunted, mourning subjects that succumb to the difficulties of reconciling with the labour of mourning translate into the melancholic subject where there is a failure to comprehend and/or 
acknowledge what really has been lost (beyond the personnage of the person and the ideality of the ideal).

This endless, ceaseless unforgiving mourning-without-end(s) which is doomed to be and remain incomplete; in constant suspension; as an interrupted and infinitely disturbed state; as impossible and interminable, bears remarkable ramifications on/for the mourning subject, for it apparently propounds that, in accordance to Derrida, the mourning subject is the melancholic subject. But Derrida's conceptualization of the melancholic subject isn't either about being incapacitated or about being immobilized but about being haunted which bestows the duty, responsibility and yearning for the dead significant other on to us.

This responsibility is the thread connecting the self unto the other whereby it becomes unthinkable to reckon with the self exempt from the other, and this relationship is always lopsided and never (to be) reciprocated. The haunting, the ghost, the spectre points to infiniteness and the death of the other which offers no absolution at least not from the responsibility of accounting for the now-dead ghost, rather bestows us with immeasurable responsibilities whereby autonomy, again in the Derridian sense, is rather a heteronomy that comes only at/from the death of the other in death and as other.

This responsibility is also the responsibility of not killing the other again wherein what has been left in the self by the dead other is a scope for 'conversation' or 'renewed exchange'- the seat for the responsibility towards the dead (Davis 2007: 154). And melancholia manages to sustain only by holding on to a fibre that threads the self and other ( $p$. 146), wherein it can no longer be deemed pathological but must be dealt with as an "ethics of death" (Bennington 2010: xixii).

The mourner, as a surviving and melancholic subject, questions any clear picture of the process of mourning while also underlining the apparently limitless intricacies and difficulties of dealing with loss. Our relation to and understanding of loss is in living with it. This prompts 
the mourning and melancholic subject to consider and question the ethical responsibilities we have to the dead other (dead/ other). This is largely a question about, as posited earlier through Krell, the meaning of life and living when faced by our own mortality and by the death of others. So, we must never get over loss but carry the loss in us and use it to think through our own existence in relation to one another.

Freud would suggest that mourning carries the other in the self which would translate to an end of the world for the other by virtue of being dead and that end must carry on through the living, mourning, haunted subject. Melancholy yearns for the failure of this mourning. And as we must then carry the other respectfully in their unique otherness where melancholy has to tussle with mourning. By keeping the other in ourselves (as part of ourselves) is an act of forgetting the other rendering melancholy as vital and necessary. Derridian melancholia is more of an ethics of living with the dead. Indeed, 'normal' mourning could result in another death of the other in order for life to go on uninterrupted, the ethics that the melancholic subject must dispense is to make sure that the dead other within us transmute into any kind of autonomy that we might find again. Melancholia is therefore a protest first and foremost against forgetting and mourning is our ethical duty to the dead.

Mourning is not only exacting, ceaseless and relentless but doomed to be incomplete, inaccessible, and impossible; it's a radical existential proposition. The dead continue in us by virtue of our fidelity and ethical dispositions by preserving their absolute singularity and unique otherness. The dead can't be archived away through a text or image as nothing more than a non-partisan object of memory but the self also has to bear the responsibility of forging conversation, of initiating dialogue in this world (the world of living among the dead) and inside of us which has been/is/and will remain disrupted and lopsided, tedious and unforgiving, infinite and interminable. 
Conclusion

When trying to make sense of the loss we have to be sensitive, not only to the loss but to the many intricacies and responsibilities which this loss provokes in us. We are not only faced with the absolute and finite truth of our mortality and the loss of our loved ones but what the meaning is for existence itself. We, the living, are obligated to allow the dead to speak to the living by mourning ethically. In order to keep the past alive in the present, a melancholic practice in its inconsolability, we have to reject the outright relinquishing of the past or the annihilation of the dead (other) by us.

In the Derridian sense, reconciliation bears the charge of being unethical because any conclusion and resolution to mourning is an act of betrayal committed against the other vis a vis the self. The haunted subject has the duty to remain in relationship to the dead through 'secret' language and concealed intimacy while dealing with the knowledge of our finiteness, our own death. This unresolvable, irreconcilable and impossible contradiction which in the practice of mourning, is the ethical responsibility. To Derrida, we are a sum of our interiorized losses. The work of mourning is doomed to be compulsory and impossible as the dead are outside of ourselves but they are proximate i.e. they are inside of us through memory and maintaining their unique and absolute alterity while conversing with us.

\section{References}

Bennington, G. (2010). Not Half No End: Militantly Melancholic Essays in Memory of Jacques Derrida. Edinburgh, Edinburgh University Press.

Bollas, C. (1987). The Shadow of the Object: Psychoanalysis of the Unthought Known. London: Free Association Books. 
Brault, P.A., \&Naas, M. (2001). Editors Introduction - To Reckon with the Dead: Jacques Derrida"s Politics of Mourning. [In:] Derrida, J . The Work of Mourning. Chicago and London: The University of Chicago Press.

Davis, C. (2007). Haunted Subjects: Deconstruction, Psychoanalysis and the Return of the Dead. Basingstoke, Hampshire: Palgrave Macmillan.

Derrida, J. (1989). Memoires for Paul de Man (Translated by Cecile Lindsay et al). New York: Columbia University Press.

Derrida, J . (1994). Spectres of Marx. (Translated by Peggy Kamuf). New York and London: Routledge.

Derrida, J . (1995). Points: Interviews, 1974-1994. (Translated by Peggy Kamuf et al). Stanford, CA: Stanford University Press.

Derrida, J . (2001). The Work of Mourning (Translated by Pascale-Anne Brault and Michael Naas). Chicago and London: The University of Chicago Press.

Derrida, J. (2001a). I Have a Taste for the Secret (Translated by Giacomo Donis). [In:] A Taste for the Secret. (Eds.) Donis, G. \& Webb, D. Cambridge, England: Polity Press.

Derrida, J. (2003). Following Theory: Jacques Derrida. [In:] Life. After. Theory. (Eds.) Payne, M. \& Schad, J . London and New York: Continuum.

Derrida, J ., \& Roudinesco, E. (2004). For What Tomorrow... A Dialogue. (Translated by J eff Fort). Stanford, CA: Stanford University Press. Derrida, J . (2005). Rams: Uninterrupted Dialogue - Between Two Infinities, The Poem (Translated by Thomas Dutoit and Philippe Romanski). [In:] Sovereignties in Question: The Poetics of Paul Celan. (Eds.) Dutoit, T. \& Pasanen, O. New York: Fordham University Press.

Freud, S. ([1917] 2006). Mourning and Melancholia (Translated by Shaun Whiteside). [In:] The Penguin Freud Reader. (Ed.) Phillips A. London: Penguin. 
Gaston, S. (2006). The Impossible Mourning of Jacques Derrida. London and New York: Continuum.

Krell. D.F. (2000). The Purest of Bastards: Works of Mourning, Art, and Affirmation in the Thought of Jacques Derrida. University Park: The Pennsylvania State University Press.

Merleau-Ponty, M. (2012). Phenomenology of Perception. (translated anew by Donald A. Landes) London \&New York: Routledge.

Miller, J .H. (2009). For Derrida. New York: Fordham University Press. Ricciardi, A. (2003). The Ends of Mourning: Psychoanalysis, Literature, and Film. Stanford: Stanford University Press.

Royle, N. (2009). In Memory of Jacques Derrida. Edinburgh: Edinburgh University Press. 